\title{
Vegetarian dietary patterns and the risk of breast cancer in a low-risk population
}

\author{
Jason A. Penniecook-Sawyers, Karen Jaceldo-Siegl, Jing Fan, Larry Beeson, Synnove Knutsen, \\ Patti Herring and Gary E. Fraser* \\ Adventist Health Study-2, Loma Linda University, Loma Linda, CA 92350, USA
}

(Submitted 9 October 2015 - Final revision received 26 January 2016 - Accepted 9 February 2016 - First published online 18 March 2016)

\section{Abstract}

Among cancers in American women, breast cancer (BC) has the second highest incidence and mortality. The association of BC with diet has been inconsistent. Studies that evaluate associations with dietary patterns are less common and reflect an individual's whole diet. We associated dietary patterns with the risk of BC in American women of the Adventist Health Study-2 (AHS-2), a prospective cohort of 96001 subjects recruited between 2002 and 2007. Answers to a previously validated FFQ were used to classify subjects to vegan, lactoovo-vegetarian, pesco-vegetarian, semi-vegetarian and non-vegetarian dietary patterns. Incident BC were identified by matching AHS-2 subjects to data from forty-eight state cancer registries. Statistical analyses used proportional hazard regression analyses with covariates that were chosen a priori. From 50404 female participants (26193 vegetarians), we identified 892 incident BC cases, with 478 cases among vegetarians. As compared with non-vegetarians, all vegetarians combined did not have a significantly lower risk (hazard ratio (HR) 0.97; CI $0 \cdot 84,1 \cdot 11 ; P=0 \cdot 64)$. However, vegans showed consistently lower (but non-significant) point estimates when compared with non-vegetarians (all cases: HR 0.78 ; CI $0.58,1.05 ; P=0.09$ ). In summary, participants in this cohort who follow a vegetarian dietary pattern did not experience a lower risk of $\mathrm{BC}$ as compared with non-vegetarians, although lower risk in vegans is possible. These findings add to the very limited literature associating vegetarian diets with $\mathrm{BC}$ risk and can assist nutritionists when evaluating the impact of these diets. The findings will also motivate further evaluation of vegan diets and their special characteristics.

\section{Key words: Breast cancer: Dietary patterns: Vegetarians: Adventists}

Breast cancer (BC) is the most common cancer in women across both developed and developing economies ${ }^{(1)}$, and this is true among American women (excluding non-melanoma skin cancers), in whom it is also the second leading cause of cancer death ${ }^{(2)}$. Potentially modifiable risk factors include breast density $^{(3)}$, body weight, smoking ${ }^{(4)}$, alcohol consumption ${ }^{(5)}$, physical activity $^{(6)}$, radiation exposure ${ }^{(7)}$, hormone replacement therapy ${ }^{(8)}$, the use of oral contraceptives ${ }^{(9)}$ and possibly diet.

It is estimated that a third of cancers could be prevented by diet alone ${ }^{(10)}$, but research findings for $\mathrm{BC}$ have not been consistent $^{(11,12)}$. Countries with high soya intake have a lower incidence of $\mathrm{BC}^{(13)}$. In some studies ${ }^{(14)}$, this protection is lost after migration to lower soya-consuming societies, providing some support for a hypothesis that dietary soya protects against BC. Micronutrients found in fruits and vegetables have also shown protective associations in some reports ${ }^{(15-20)}$. Associations of dietary fats with $\mathrm{BC}$ have also been inconsistent in the literature, although results for SFA often tend towards an increased risk ${ }^{(21-27)}$. Possible confounding by smoking habits and especially alcohol intake is of concern in some of these studies. The Continuous Update Project Report from the
World Cancer Research Fund/American Institute of Cancer Research (WCRF/AICR) ${ }^{(12)}$ lists only total fat in postmenopausal women as having limited but suggestive evidence for causality and that the evidence for other dietary factors in either pre- or postmenopausal women is limited and inconclusive.

Individual foods such as fruits or vegetables, or nutrients, account for only a part of a diet. Studies that evaluate effects of whole diets by focusing on dietary patterns are less common, but they have suggested protective effects for BC from 'Mediterranean' diets, or 'prudent' diets that emphasise vegetables ${ }^{(28-34)}$. However, definitions of these patterns often include or overlap with vegetarian dietary patterns, and, confusingly, patterns with the same label may be defined differently in different studies, although they have some common features.

There is a paucity of available evidence concerning the effects of vegetarian dietary patterns on risk of $\mathrm{BC}^{(35-37)}$, and again definitions may differ between studies. In an earlier study of California Adventists that included many vegetarians, no strong dietary associations with BC could be identified, although there was some limited evidence of hazard associated

Abbreviations: AHS-2, Adventist Health Study-2; BC, breast cancer; ER, oestrogen receptor; HR, hazard ratio; PR, progesterone receptor.

* Corresponding author: G. E. Fraser, fax +1 909558 0126, email gfraser@llu.edu 
with higher cheese consumption ${ }^{(38)}$. Similarly, more recent work from EPIC-Oxford did not detect associations, although their vegan participants were proportionately few ${ }^{(39)}$.

Here, we analyse associations between vegetarian dietary patterns and $\mathrm{BC}$ in women participating in the Adventist Health Study-2 (AHS-2), which has rates of BC that are $>20 \%$ lower than usual ${ }^{(40)}$, very low rates of tobacco and alcohol consumption, a wide diversity of dietary habits and overall good health. Diet is classified into five patterns (vegan, lacto-ovo-vegetarian, pesco-vegetarian, semi-vegetarian and non-vegetarian). Our a priori hypothesis is that risk of $\mathrm{BC}$ will be lower in the vegetarian (especially vegan, lacto-ovo- and pesco-vegetarian) groups than in the non-vegetarians.

\section{Methods}

\section{Ethics statement}

This study was conducted according to the guidelines laid down in the Declaration of Helsinki, and all procedures involving human subjects were approved by the Institutional Review Board of Loma Linda University. Written informed consent was obtained from all subjects.

\section{Study design and population}

The AHS-2 is a prospective cohort of 96001 subjects in the USA and Canada that was designed to study associations between lifestyle and cancer risks. Subjects were recruited and enroled with the completion of the baseline questionnaire between 2002 and 2007, hence providing dietary information at that time. The cohort includes 62511 women (17952 female black subjects of American or Caribbean descent) and has been described previously ${ }^{(41)}$. Mean follow-up time was $7 \cdot 8$ years.

Here we include participants from forty-eight states and Washington, DC, where matching with cancer registries had been completed; thus, we include cases diagnosed by the end of 2011 for thirty-three registries (including DC), 2010 for an additional ten states, 2009 for three states and 2008 for the remaining two states. We excluded Canadian participants (as vital status had not been established for all), also those with a prevalent cancer, age $<35$ years, participants with questionnaires having more than seventy FFQ missing or $\mathrm{kJ} / \mathrm{kcal}$ intake $<500$ or $>4500$, as well as also women who reported never having had a menstrual period. Thus, 50404 women were finally included in the analysis.

\section{Dietary assessment and cancer ascertainment}

Dietary patterns were determined according to the intake frequency (thinking over the past 1 year) of specific foods (red meat, poultry, fish, eggs and dairy products) using a previously validated FFQ. The validation was against six 24-h dietary recalls in a calibration sub-study. The validity correlations for foods of relevance here for non-black subjects are red meat (0.76); poultry (0.76); fish (0.53); dairy protein and fat $(0.77,0.66)$; and eggs $(0.64)$. Similar results for Black subjects are $0.72 ; 0.77 ; 0.57 ; 0.58,0.56$; and $0.52^{(42,43)}$.
Categories of intake frequency on the FFQ ranged from 'never or rarely' to ' $>2$ times/d' for the meat groups, or to ' $>6$ times/d' for the dairy group. Meats included red meats (beef, lamb), poultry (chicken, turkey) and fish (salmon, white fish, tuna, other fish). Dairy variables included low-fat or regular milk and its derivatives (cheese, cottage cheese, butter, yogurt, ice cream and so on). There were three possible serving sizes: a supplied standard, 'half or less' and 'half or more' of this standard.

Subjects were classified as 'vegan' if their intake of egg, dairy or meat products was less than once per month; as 'lactoovo-vegetarians' if their intake of fish, poultry and red meats was less than once per month and their intake of eggs or dairy products was more than or equal to once per month; as 'pesco-vegetarian' if fish intake was $\geq 1$ times/month, while red meats and poultry were consumed less than once per month, but no constraints on dairy products or eggs; as 'semi-vegetarians' if intake of red meats, poultry or fish, but not only fish was more than or equal to once per month but less than once per week; and as 'non-vegetarians' if intake of red meat, poultry or fish (but not only fish) was more than or equal to once per week. A dichotomous 'vegetarian' variable that combined vegans, lacto-, pesco- and semi-vegetarians was used for comparison with non-vegetarians to preserve adequate numbers in some analyses.

As described elsewhere in detail ${ }^{(44,45)}$, these dietary categories differ in major ways by their intake of different foods and nutrients. The more vegetarian categories have profiles generally thought to be more healthy (greater intakes of carotenoids, folate, isoflavones, $\alpha$-linolenic acid, fibre, $\mathrm{Mg}, \mathrm{K}$, fruits, vegetables, nuts, legumes, soya foods, as well as the lesser intakes of animal products). The meat intakes of the non-vegetarian group in AHS-2 are lower than those in the general population, with mean intakes of about $18 \mathrm{~g} / \mathrm{d}$ of red meats, $22 \mathrm{~g} / \mathrm{d}$ of poultry and $19 \mathrm{~g} / \mathrm{d}$ of fish ${ }^{(45)}$.

Cancers were mainly identified by linkage to cancer registries. An AHS-2 programmer performed the match where possible, and in other situations he was usually online with the registry staff during the match. The AHS-2 programmer used Registry Plus ${ }^{\mathrm{TM}}$ Link Plus ${ }^{(46)}$ matching software, and this was often also used in the other matches. The software provides a score that was used to categorise potential matches as definite non-matches, definite matches and a remaining inconclusive category. Most of the inconclusive matches were resolved by the computer application of matching codes based on twelve matching variables. These had been developed by consensus to further identify matches and non-matches. A much smaller inconclusive zone remained that was resolved by manual review, usually in collaboration with registry staff.

As a backup, biennial hospitalisation history forms (completed by $75 \%$ of subjects) included questions about recent hospitalisations and cancer diagnoses. Additional incident cases from this source (finally constituting about $2 \%$ of the total) were validated first by phone calls to the subjects, and those not excluded were finally verified by obtaining medical records ${ }^{(47)}$. Our diagnostic information contained hormone receptor status for $82 \%$ of $\mathrm{BC}$ cases. 


\section{Covariates}

Covariate data were collected at enrolment to AHS-2 in the baseline questionnaire. We selected potential covariates to include established or suspected non-dietary risk factors. Less established risk factors $^{(4,5,48-50)}$ were retained in the model if they changed the $\beta$-coefficients of interest by at least $10 \%$. Race was self-defined by participants (Black if participants self-identified as African-American, West-Indian/Caribbean, African or other Black and non-Black otherwise). In regression analyses, BMI was modelled as underweight $\left(<18.5 \mathrm{~kg} / \mathrm{m}^{2}\right)$, normal weight as a reference $\left(18.5-24.99 \mathrm{~kg} / \mathrm{m}^{2}\right)$, overweight $\left(25-29.99 \mathrm{~kg} / \mathrm{m}^{2}\right)$ and three degrees of obesity $\left(1^{\circ}: 30-34 \cdot 99,2^{\circ}: 35-39 \cdot 99,3^{\circ}: \geq 40\right)$. Product terms were also included between BMI categories and menopausal status to allow the BMI effect to depend on menopausal status. Height in inches is reported as a continuous variable. Breastfeeding was a continuous variable corresponding to the sum of breastfeeding months as reported by participants. Physical activity was reported in minutes per week of vigorous activities (brisk walking, jogging, bicycling and so on). Family history of cancer was considered to be positive when BC or ovarian cancer was reported in paternal or maternal first-degree relatives and/or siblings. Our BC screening variable identifies subjects who enroled after the age of 42 years and reported mammography during the previous 2 years. Participants who had reported a complete cessation of their natural periods because of natural causes, radiation, chemotherapy, bilateral oophorectomy, hysterectomy after the age of 55 years (the 90th percentile of natural age at menopause), as well as all participants 60 years or older at baseline, were considered menopausal. In addition, women $<60$ years of age (or $<56$ years for those posthysterectomy) whose 'doctors considered them to be perimenopausal' were counted as menopausal. However, their age at menopause was calculated as age at enrolment plus 2 years, considering that 4 years is a common duration for perimenopausal status ${ }^{(51)}$. For others, age at menopause was defined as the reported age at menopause for menopausal women or age at bilateral oophorectomy in the absence of oral contraceptive therapy. Age at birth of the first child was classified as either those who had their first birth before age 30 years or those that were either nulliparous or gave birth after the age of 30 years. The use of birth control pills was scored as ever or never. Hormone replacement therapy was assigned as oestrogen or progesterone therapy for purposes other than contraception. Hormone replacement therapy was considered relevant if it lasted $>1$ year and was used within 5 years of enrolment. Smoking was entered as a binary variable for lifetime use (ever/never). Alcohol was considered positive in those who reported any consumption at enrolment or within the previous 2 years.

Educational status was coded in three levels: grade school, trade school or high school diploma; some college education; and college degree or higher. This variable is used as a surrogate for socio-economic class.

\section{Statistical methods}

Attained age was the time variable used in the proportional hazards regression analyses. The models were left-censored at age of entry to the study. Right censoring occurred at the first date of any of the following: $\mathrm{BC}$ diagnosis, death, loss to follow-up or the last date of follow-up. The latest year-end for which a subject's home-state cancer registry had complete data when we matched was the date of last follow-up for subjects not previously satisfying other censoring criteria. The statistical model included four indicator variables for the five dietary patterns (non-vegetarian was the reference pattern), as well as a race variable $(1=\mathrm{Black})$, and other covariates as indicated in footnotes.

Some variables were relevant only when nested within a population sub-group. In regression models, variables indicating the subgroup (e.g. menopausal/non-menopausal women) were included as main effects along with products between these and the relevant nested exposures of interest (e.g. hormone replacement therapy).

Because BMI may be an intermediary between diet and cancer, models are reported with and without BMI as a covariate. Cancers were coded, where the data were available, as oestrogen or progesterone receptor (ER/PR) positive or negative. Competing risk analysis ${ }^{(52)}$ was used to measure the risk of the different cancer subgroups (ER/PR status).

Missing data were handled through multiple imputation (five data sets with imputed missing data) using the Hmisc package in the $\mathrm{R}$ language conditional on all variables included in the Cox model. This uses predictive mean matching, and on inspection it produced frequencies of vegetarian patterns (where there had been missing data) similar to those of other subjects. Variances of $\beta$-coefficients were estimated using all imputed data sets ${ }^{(53)}$. Missing dietary data were imputed at the level of individual FFQ (between 3 and $8 \%$ missing for particular questions), and could usually be guided by results from a random subset of missing data for the same variables that had been filled-in by telephone contact ${ }^{(54)}$. Dietary patterns were then assigned using the imputed data sets.

\section{Results}

During the 393554 person-years of follow-up (average of $7 \cdot 8$ years/person), we identified 892 cases of BC: 414 cases in the non-vegetarian group and 478 cases in vegetarians. Age at enrolment ranged from 35 to 110 years in the full cohort, whereas for $\mathrm{BC}$ cases age at enrolment ranged from 35 to 100 years.

Age and race-standardised means, or proportions, for variables of interest, stratified by dietary category, are shown in Table 1. Approximately half of the cohort was non-vegetarian. Compared with participants with other dietary patterns, they had lower educational attainment, an earlier age at first childbirth and lower age at menopause.

They had the highest BMI values, and the highest proportions that used oral birth control pills, or had a positive family history of cancer, but the lowest levels of physical activity. In contrast, vegans had a much lower mean BMI, had the lowest rates of hormone replacement therapy, lowest use of oral birth control pills, the lowest parity, as well as the least compliance with recommendations for cancer screening, but the highest levels of 
Table 1. Distribution of participants, dietary patterns and covariates by case/non-case status

\begin{tabular}{|c|c|c|c|}
\hline & Non-cases & Cases & $P$ \\
\hline \multicolumn{4}{|l|}{ Dietary pattern (age-standardised to full cohort) } \\
\hline Vegetarian & $51.9 \%$ & $53.1 \%$ & $<0.0001$ \\
\hline Vegan & $7.5 \%$ & $5.5 \%$ & $<0.0001$ \\
\hline Lacto-ovo-vegetarian & $28.4 \%$ & $31.3 \%$ & $<0.0001$ \\
\hline Pescetarian & $10 \cdot 3 \%$ & $10 \cdot 2 \%$ & 0.23 \\
\hline Semi-vegetarian & $5.8 \%$ & $6.1 \%$ & 0.0009 \\
\hline Non-vegetarian & $48.1 \%$ & $46.9 \%$ & $<0.0001$ \\
\hline All subjects & 49512 & 892 & NA \\
\hline \multicolumn{4}{|l|}{ Covariates (age-standardised to full cohort) } \\
\hline Age at censoring (years) (mean) & $64 \cdot 77$ & 61.82 & $<0.0001$ \\
\hline Age at menarche (years) (mean) & $12 \cdot 54$ & 12.35 & 0.0003 \\
\hline Age at first birth (years) (mean) & 24.04 & 24.44 & 0.051 \\
\hline Age at natural menopause (years) (mean) & $47 \cdot 85$ & 48.67 & 0.0008 \\
\hline BMI $\left(\mathrm{kg} / \mathrm{m}^{2}\right)$ (mean) & $27 \cdot 38$ & $27 \cdot 58$ & 0.37 \\
\hline Height (inches) (mean) & $64 \cdot 24$ & $64 \cdot 39$ & 0.16 \\
\hline Menopause (\%) & $69.0 \%$ & $69.0 \%$ & 0.60 \\
\hline Hormone replacement therapy (\% among menopausal women) & $37.7 \%$ & $43.6 \%$ & $<0.0001$ \\
\hline Oral birth control (\%) & $60.0 \%$ & $61.5 \%$ & $<0.0001$ \\
\hline Family history of breast cancer (\%) & $11.7 \%$ & $22 \cdot 1 \%$ & $<0.0001$ \\
\hline Family history of ovarian cancer $(\%)$ & $4.1 \%$ & $4.0 \%$ & 0.51 \\
\hline Family history of breast or ovarian cancer (\%) & $15.0 \%$ & $25 \cdot 2 \%$ & $<0.0001$ \\
\hline Parity (\% at baseline) & $84.3 \%$ & $84.1 \%$ & 0.051 \\
\hline Breastfeeding (total months) (mean) & $12 \cdot 26$ & 11.55 & 0.16 \\
\hline Number of children & $2 \cdot 71$ & 2.60 & 0.018 \\
\hline Some college or higher & $78.3 \%$ & $78.1 \%$ & 0.25 \\
\hline Screening ( $\%$ of mammography last 2 years) & $71.8 \%$ & $77 \cdot 1 \%$ & $<0.0001$ \\
\hline Physical activity (min/week) & 74.43 & $75 \cdot 75$ & 0.71 \\
\hline Smoking (\% ever) & $16 \cdot 2 \%$ & $14.1 \%$ & $<0.0001$ \\
\hline Alcohol (within 2 years of enrolment) & $10 \cdot 9 \%$ & $12.6 \%$ & $<0.0001$ \\
\hline
\end{tabular}

physical activity. Table 2 summarises hazard ratios (HR) from proportional hazards models, with covariates chosen as described above. There was no evidence of a different risk for $\mathrm{BC}$ in vegetarians compared with non-vegetarians. This was true in both pre- and postmenopausal women, although CI were wide in the first group.

However, the point estimate for vegans suggested the possibility of lower risk in this group (HR 0.78; 95\% CI 0.58 , $1.05 ; P=0.09$ ), although this fell short of statistical significance particularly if one takes account of the multiple testing among the vegetarian categories. Adding BMI to the model shifted the point estimate towards the null (HR 0.84; $95 \%$ CI 0.62, 1.13; $P=0.25)$ - the change in point estimate suggesting some mediation of any vegan dietary effect by BMI. Changing the reference group to include also pesco- and semi-vegetarians did not substantially alter these results.

Table 3 presents HR analysed by race. As in the previous analyses, there was no evidence that vegetarians were protected overall. Again vegans had the lowest risk in each racial group, but without statistical significance.

Results stratified by hormone receptor status (ER+/PR+; ER-/PR-; *ER+/PR-) are not shown in detail. With the exception of $\mathrm{ER}+\mathrm{PR}+$, numbers are small resulting in inadequate power. For the $\mathrm{ER}+/ \mathrm{PR}+$ cancers there was no convincing evidence of any association with the vegetarian categories.

Certain covariates were also independently associated with $\mathrm{BC}$ risk (not shown in the tables). An earlier age at menarche (menarche before age 14 years) was associated with an increase of risk (HR 1.19; $95 \%$ CI 1.01, 1.42; $P=0 \cdot 043$ ). Family history of
$\mathrm{BC}$ was associated with an almost 2-fold increase in risk when compared with others (HR 1.91; 95\% CI 1.63, 2.24; $P<0.001$ ). Within the ages often associated with perimenopausal years, a woman who was already menopausal was at a lower risk than a woman who was still premenopausal (HR 0.51; 95\% CI 0.29, $0.91 ; P=0 \cdot 024)$. Appropriate screening was possibly associated with higher risk (HR 1.172; $95 \%$ CI 0.99, 1.39; $P=0.067$ ).

\section{Discussion}

\section{Key findings}

The main result is that in this study there was no convincing evidence that vegetarians as a group had lower risk of BC than non-vegetarians either in pre- or postmenopausal, or in Black or White, women. The CI for the total group were relatively narrow, although a small protective effect of vegetarianism could not be excluded. This is in agreement with the findings of the EPIC-Oxford Study, another cohort containing many vegetarians $^{(55)}$. Nevertheless, it is of some interest that in AHS-2 the vegan diet had a stronger and more consistent negative association with risk of $\mathrm{BC}$ than other dietary groups. The estimated relative risks in comparison with non-vegetarians were between 0.70 and 0.82 in different subgroups. These included pre- and postmenopausal women, Black women and those with $\mathrm{ER}+/ \mathrm{PR}+$ cancers. However, in none of these groups could chance be excluded as an explanation, and the numbers of cases were often small. BMI is considerably lower in vegans, and as a mediating variable this could explain a part of any underlying effect. As far as we know, this is the largest 
Table 2. Dietary pattern and breast cancer incidence* (Hazard ratios (HR) and $95 \%$ confidence intervals)

\begin{tabular}{|c|c|c|c|c|c|c|c|c|}
\hline & \multirow[b]{2}{*}{ Participants } & \multirow[b]{2}{*}{ Cases } & \multicolumn{3}{|c|}{ No BMI } & \multicolumn{3}{|c|}{ With BMI } \\
\hline & & & $\mathrm{HR}$ & $95 \% \mathrm{Cl}$ & $P$ & $\mathrm{HR} \dagger$ & $95 \% \mathrm{Cl}$ & $P$ \\
\hline \multicolumn{9}{|l|}{ Totalł } \\
\hline Non-vegetarian & 24211 & 414 & 1.00 & Ref. & & 1.00 & Ref. & \\
\hline Vegan & 3748 & 52 & 0.78 & $0.58,1.05$ & 0.09 & 0.84 & $0 \cdot 62,1 \cdot 13$ & 0.25 \\
\hline Lacto & 14336 & 289 & 1.05 & $0.89,1.23$ & 0.57 & 1.08 & $0.92,1.27$ & 0.34 \\
\hline Pesco & 5179 & 88 & 0.91 & $0.71,1.17$ & 0.48 & 0.94 & $0.73,1.21$ & 0.65 \\
\hline Semi & 2930 & 49 & 0.91 & $0.67,1.23$ & 0.52 & 0.91 & $0.68,1.24$ & 0.56 \\
\hline All vegetarians & 26193 & 478 & 0.97 & $0.84,1.11$ & 0.64 & 1.00 & $0.87,1 \cdot 16$ & 0.97 \\
\hline \multicolumn{9}{|l|}{ Postmenopausal } \\
\hline Non-vegetarian & 16215 & 333 & 1.00 & Ref. & & 1.00 & Ref. & \\
\hline Vegan & 2700 & 44 & 0.77 & $0.55,1.06$ & $0 \cdot 11$ & 0.83 & $0.60,1 \cdot 16$ & 0.27 \\
\hline Lacto & 10096 & 248 & 1.06 & $0.89,1.26$ & 0.53 & $1 \cdot 10$ & $0.92,1.31$ & 0.31 \\
\hline Pesco & 3648 & 69 & 0.85 & $0.64,1.13$ & 0.25 & 0.88 & $0.66,1 \cdot 18$ & 0.37 \\
\hline Semi & 2148 & 34 & 0.73 & $0.53,1.06$ & $0 \cdot 10$ & 0.74 & $0.52,1.06$ & $0 \cdot 10$ \\
\hline All vegetarians & 18592 & 395 & 0.94 & $0.80,1.09$ & 0.40 & 0.97 & $0.83,1.14$ & 0.73 \\
\hline \multicolumn{9}{|l|}{ Premenopausal§ } \\
\hline Non-vegetarian & 7996 & 81 & 1.00 & Ref. & & 1.00 & Ref. & \\
\hline Vegan & 1048 & 8 & 0.81 & $0.38,1.70$ & 0.58 & 0.86 & $0.40,1.82$ & 0.69 \\
\hline Lacto & 4240 & 41 & 0.96 & $0.63,1.45$ & 0.84 & 0.98 & $0.64,1.48$ & 0.91 \\
\hline Pesco & 1531 & 19 & 1.25 & $0.75,2.10$ & 0.40 & 1.27 & $0.75,2 \cdot 14$ & 0.38 \\
\hline Semi & 782 & 15 & 1.96 & $1.12,3.43$ & 0.019 & 1.95 & $1.11,3.42$ & 0.020 \\
\hline All vegetarians & 7601 & 83 & $1 \cdot 12$ & $0.80,1.57$ & 0.52 & $1 \cdot 14$ & $0.81,1.61$ & 0.44 \\
\hline
\end{tabular}

Ref., referent values.

* Time variable: attained age. Reference group: non-vegetarians.

† For total cases the product menopausal status $\times$ BMI was used to allow a different BMI association conditional on menopausal status.

$\ddagger$ Adjusted for: race, height, physical activity, family history of cancer, mammography in the last 2 years after age 42 years, age at menopause, age at menarche, birth control pills, hormone replacement therapy, age at first child, number of children, breastfeeding, educational level, smoking, alcohol, BMI (as indicated).

$\S$ Adjusted as for the total group but excluding age at menopause and hormone replacement therapy.

Table 3. Dietary pattern and breast cancer incidence by race*

(Hazard ratios (HR) and $95 \%$ confidence intervals)

\begin{tabular}{|c|c|c|c|c|c|c|c|c|}
\hline & \multirow[b]{2}{*}{ Participants } & \multirow[b]{2}{*}{ Cases } & \multicolumn{3}{|c|}{ No BMI } & \multicolumn{3}{|c|}{ With BMI } \\
\hline & & & $\mathrm{HR}$ & $95 \% \mathrm{Cl}$ & $P$ & $\mathrm{HR}$ & $95 \% \mathrm{Cl}$ & $P$ \\
\hline \multicolumn{9}{|l|}{ Non-black } \\
\hline Non-vegetarian & 14957 & 291 & 1.00 & Ref. & & 1.00 & Ref. & \\
\hline Vegan & 2888 & 43 & 0.80 & $0.58,1.12$ & $0 \cdot 19$ & 0.86 & $0 \cdot 62,1 \cdot 21$ & 0.39 \\
\hline Lacto & 12331 & 250 & 1.00 & $0.84,1.19$ & 0.99 & 1.02 & $0.85,1.23$ & 0.80 \\
\hline Pesco & 3063 & 61 & 0.91 & $0.68,1.23$ & 0.55 & 0.94 & $0.70,1.26$ & 0.67 \\
\hline Semi & 2354 & 39 & 0.83 & $0.59,1.17$ & 0.28 & 0.83 & $0.59,1.18$ & 0.30 \\
\hline All vegetarians & 20636 & 393 & 0.94 & $0.80,1 \cdot 10$ & 0.45 & 0.97 & $0.82,1.14$ & 0.68 \\
\hline Total & 35593 & 684 & & & & & & \\
\hline \multicolumn{9}{|l|}{ Black } \\
\hline Non-vegetarian & 9254 & 123 & 1.00 & Ref. & & 1.00 & Ref. & \\
\hline Vegan & 860 & 9 & 0.70 & $0.35,1.38$ & 0.30 & 0.77 & $0.39,1.55$ & 0.46 \\
\hline Lacto & 2005 & 39 & 1.31 & $0.90,1.90$ & 0.16 & 1.39 & $0.95,2.05$ & 0.09 \\
\hline Pesco & 2116 & 27 & 0.94 & $0.60,1.48$ & 0.80 & 1.00 & $0.63,1.58$ & 0.99 \\
\hline Semi & 576 & 10 & 1.25 & $0.64,2.43$ & 0.51 & 1.29 & $0.66,2.51$ & 0.46 \\
\hline All vegetarians & 5557 & 85 & 1.08 & $0.80,1.45$ & 0.62 & $1 \cdot 15$ & $0.85,1.56$ & 0.37 \\
\hline Total & 14811 & 208 & & & & & & \\
\hline
\end{tabular}

Ref., referent values.

* Time variable: attained age. Reference group: non-vegetarians. Adjusted for: height, physical activity, family history of cancer, mammography in the last 2 years after age 42 years, age at menopause, age at menarche, birth control pills, hormone replacement therapy, age at first child, number of children, breastfeeding, educational level, smoking, alcohol, and $\mathrm{BMI} \times$ menopausal status (as indicated).

available single study of $\mathrm{BC}$ risk among different types of vegetarian women, and the possibility of lower rates in vegans is of some interest. Previously ${ }^{(47)}$, we had noted that vegans in AHS-2 had a tendency to lower incidence rates of female cancers in general (HR $0.71 ; 95 \% \mathrm{CI} 0 \cdot 50,1 \cdot 01)$.
Although the evidence for the association between diet and $\mathrm{BC}$ is currently limited ${ }^{(12)}$, many studies have found a reduction of risk when there is a higher intake of fruit and vegetables $(28,31,32,34,36)$. This is particularly so for postmenopausal $\mathrm{BC}^{(29,31,32,34,56)}$, which may have stronger links to lifestyle and 
environmental factors than premenopausal cancer ${ }^{(57,58)}$. Contrary to this opinion, however, an analysis in American Black women found stronger associations of a prudent dietary pattern with premenopausal BC. The few reports associating diet with particular hormone receptor variants of $\mathrm{BC}$ have often found greater protective associations of fruit and vegetables for risk of ER- $\mathrm{BC}^{(28-30,32,56)}$. The association of red meat, poultry, fish, dairy and soya consumption with risk of $\mathrm{BC}$ has been less consistent ${ }^{(36,37,55,59,60)}$.

Reported associations between specific dietary patterns having some overlap with vegetarianism and $\mathrm{BC}$ are relatively few. Although several such studies suggest a protective effect $^{(28-34,56,59)}$, the WCRF/AICR report considers the evidence inconclusive $^{(12)}$. This may be in part because dietary patterns that share similar names sometimes have different definitions (e.g. 'prudent', 'healthy' and 'Western' dietary patterns), thus limiting the interpretation of results across studies.

We have reported previously ${ }^{(44,45)}$ that, compared with the other dietary patterns in AHS-2, vegans are more physically active and have lower intake of energy-dense nutrients, lower $\mathrm{Na}$ intake, the lowest intakes of animal and dairy proteins, but a higher intake of foods that are rich in fibre, vitamins and plant-based proteins (e.g. fruits, vegetables, whole grains, nuts, soya). They also have a lesser history of alcohol use. These characteristics satisfy most of the American Cancer Society guidelines and the WCRF/AICR recommendations for the prevention of cancer. Catsburg et al. ${ }^{(61)}$, found that subjects meeting all $v$. only one of these criteria experienced a $31 \%$ lower BC risk. Their analysis suggested a 4-6\% lower risk for each additional recommendation that was met.

Several possibly protective mechanisms against cancer can be identified that are associated with the higher consumption of fruit, vegetables ${ }^{(47,62-65)}$ and soya ${ }^{(13,66)}$ and a lower BMI, characteristics typical of most vegans in this population. Higher intakes of non-essential amino acids, characteristic of vegan diets, regulate the insulin-glucagon axis ${ }^{(67-69)}$, and there are metabolic effects that include greater tissue sensitivity to insulin, and also decreased hepatic production and serum levels of insulin-like growth factor-1. Fruits and vegetables may provide an antioxidant environment, cell membrane protection, reduction and scavenging of nitrite and free-radical blocking ${ }^{(64)}$. These properties can potentially influence cancer progression and development through inhibition of metastasis, induction of apoptosis, anti-proliferative activity and inhibition of protein kinase activity ${ }^{(70)}$. Soya has been hypothesised to reduce BC risk by shifting oestrogen metabolites that are genotoxic towards other inactive forms ${ }^{(63,66)}$. Soya is also known to have anti-proliferative, pro-apoptotic, antiangiogenic, antioxidative and anti-inflammatory effects ${ }^{(13)}$.

\section{Study strengths and limitations}

We evaluated the association of $\mathrm{BC}$ with four vegetarian dietary patterns representing a wide range of dietary habits. This and the relatively large number of vegans provide unusual (but for vegans at this time still relatively low) statistical power to test these hypotheses. Other advantages include the large number of Black participants and the reduced potential for confounding because of this population's abstinence from, or very low use of, alcohol and tobacco.

However, this is an observational study that inevitably contains errors in the dietary data, although in this population dietary patterns can probably be assigned with relatively good validity. Another limitation is the low meat consumption of the reference group (on average about $54 \mathrm{~g} / \mathrm{d}$ ) that may cause an underestimation of the effect of a vegetarian diet as compared with a more typical non-vegetarian diet.

Finally, confounding is always a possibility despite adjustment for known correlates of vegetarianism and BC. Although we adjusted for screening (mammography), which had a borderline significant association with higher rates, residual confounding is possible. Two sensitivity analyses were performed to evaluate this possibility. First, when the screening variable was removed from the model, the association with vegans changed only from 0.77 to 0.74 . Second, it is possible that vegans may have delayed their ages at cancer diagnosis because of their lower screening rates. Thus, for this sensitivity analysis, 1 year was subtracted from the age at censoring (for any cause) in all subjects who did not screen according to recommendations. This brought forward the age at diagnosis of $\mathrm{BC}$ in these subjects, and also eliminated observations in the year before censoring for other causes (when there could have been a missed early BC because of lack of screening). Next, the association with vegans again only changes from 0.77 to $0 \cdot 76$. Thus, this suggests that any residual confounding from this source is likely to be minor.

\section{Conclusions}

In conclusion, participants in this cohort who follow a vegetarian dietary pattern overall did not experience a lower risk of BC as compared with non-vegetarians. However, those adhering to a vegan dietary pattern showed consistently lower point estimates in various subgroups but these were not statistically significant. Numbers of cancers in vegans were relatively small, and these analyses should be repeated in the AHS-2 cohort after a longer follow-up to determine whether the same trends continue when power is greater.

\section{Acknowledgements}

The authors thank Hanni Bennett, Sonja Hall and Jessica Castro, Research Associates, Adventist Health Studies, School of Public Health, Loma Linda University, for providing support to carry out the study. Cancer incidence data have been provided by the 'Alaska Cancer Registry', 'Alabama Statewide Cancer Registry', 'Arizona Cancer Registry', 'Arkansas Central Cancer Registry', 'California Cancer Registry', 'Colorado Central Cancer Registry', 'Connecticut Tumor Registry', 'District of Columbia Cancer Registry', 'Delaware Cancer Registry', 'Florida Cancer Data System', 'Georgia Comprehensive Cancer Registry', 'Hawaii Tumor Registry', 'Cancer Data Registry of Idaho', 'Iowa Cancer Registry', 'Illinois State Cancer Registry', 'Indiana State Cancer Registry', 'Kansas Cancer Registry', 'Kentucky Cancer Registry', 'Louisiana Tumor Registry', 'Maryland Cancer 
Registry', 'Massachusetts Cancer Registry', 'Michigan Cancer Surveillance System', 'Minnesota Cancer Surveillance System', 'Mississippi Cancer Registry', 'Missouri Cancer Registry and Research Center', 'Montana Central Tumor Registry', 'Nebraska Cancer Registry', 'Nevada Central Cancer Registry', 'New Hampshire State Cancer Registry', 'New Jersey State Cancer Registry', 'New Mexico Tumor Registry', 'New York State Cancer Registry', 'North Carolina Central Cancer Registry', 'North Dakota Statewide Cancer Registry', 'Ohio Cancer Incidence Surveillance System', 'Oklahoma Central Cancer Registry', 'Oregon State Cancer Registry', 'Pennsylvania Cancer Registry', 'Rhode Island Cancer Registry', 'South Carolina Central Cancer Registry', 'South Dakota Cancer Registry', 'Tennessee Cancer Registry', 'Texas Cancer Registry', 'Utah Cancer Registry, NCI Contract HHSN261201300071', 'Vermont Cancer Registry', 'Virginia Cancer Registry', 'Washington State Cancer Registry', 'West Virginia Cancer Registry', 'Wyoming Cancer Surveillance Program'. The results reported here and the conclusions based on them are the sole responsibility of the authors.

This study was funded by National Institutes of Health (NIH)/ National Cancer Institute (NCI): grant no. 5U01CA152939 (G. E. F.) and World Cancer Research Fund, UK: grant no. 2009/93 (G. E. F.). Neither the NIH nor the World Cancer Research Fund, UK had a role in the study design, conduct of the study, analysis of data, interpretation of findings or the preparation of the manuscript.

G. E. F., S. K., L. B. and K. J.-S. formulated the research question. G. E. F. and J. A. P.-S. designed the study. G. E. F., P. H., K. J.-S., L. B. and S. K. carried it out. J. A. P.-S. and J. F. analysed the data. J. A. P.-S. and G. E. F. wrote the manuscript. All authors critically reviewed the manuscript.

The authors declare that there are no conflicts of interest.

\section{References}

1. American Cancer Society (2011) Global Cancer Facts and Figures, 2nd ed. Atlanta, GA: American Cancer Society.

2. Siegel R, Naishadham D \& Jemal A (2013) Cancer statistics, 2013. CA Cancer J Clin 63, 11-30.

3. Tice JA, O'Meara ES, Weaver DL, et al. (2013) Benign breast disease, mammographic breast density, and the risk of breast cancer. J Natl Cancer Inst 105, 1043-1049.

4. Johnson KC, Miller AB, Collishaw NE, et al. (2011) Active smoking and secondhand smoke increase breast cancer risk: the report of the Canadian Expert Panel on Tobacco Smoke and Breast Cancer Risk (2009). Tob Control 20, e2.

5. Afolabi IR (2007) Towards prevention of breast cancer in the Pacific: influence of diet and lifestyle. Health Promot Pacific 14, 67-70.

6. Wu Y, Zhang D \& Kang S (2013) Physical activity and risk of breast cancer: a meta-analysis of prospective studies. Breast Cancer Res Treat 137, 869-882.

7. Laden F \& Hunter DJ (1998) Environmental risk factors and female breast cancer. Annu Rev Public Health 19, 101-123.

8. Collaborative Group on Hormonal Factors in Breast Cancer (1997) Breast cancer and hormone replacement therapy: collaborative reanalysis of data from 51 epidemiological studies of 52,705 women with breast cancer and 108,411 women without breast cancer. Lancet 350, 1047-1059.

9. Steiner E, Klubert D \& Knutson D (2008) Assessing breast cancer risk in women. Am Fam Physician 78, 1361-1366.
10. Levshin VF (1985) [Development of criteria for assessing the individual risk of breast cancer]. Vopr Onkol 31, 30-35.

11. Michels KB, Mohllajee AP, Roset-Bahmanyar E, et al. (2007) Diet and breast cancer: a review of the prospective observational studies. Cancer 109, 2712-2749.

12. World Cancer Research Fund/American Institute for Cancer Research (WCRF/AICR) (2010) Continuous Update Project Report. Food, Nutrition, Physical Activity, and the Prevention of Breast Cancer. London: WCRF International.

13. Wada K, Nakamura K, Tamai Y, et al. (2013) Soy isoflavone intake and breast cancer risk in Japan: from the Takayama study. Int J Cancer 133, 952-960.

14. Kaur JS (2000) Migration patterns and breast carcinoma. Cancer 88, 1203-1206.

15. Eliassen AH, Hendrickson SJ, Brinton LA, et al. (2012) Circulating carotenoids and risk of breast cancer: pooled analysis of eight prospective studies. J Natl Cancer Inst 104, 1905-1916.

16. Gandini S, Merzenich H, Robertson C, et al. (2000) Meta-analysis of studies on breast cancer risk and diet: the role of fruit and vegetable consumption and the intake of associated micronutrients. Eur J Cancer 36, 636-646.

17. Harris HR, Orsini N \& Wolk A (2014) Vitamin C and survival among women with breast cancer: a meta-analysis. Eur $J$ Cancer 50, 1223-1231.

18. Wu W, Kang S \& Zhang D (2013) Association of vitamin $B_{6}$, vitamin $\mathrm{B}_{12}$ and methionine with risk of breast cancer: a dose-response meta-analysis. Br J Cancer 109, 1926-1944.

19. Gong Z, Ambrosone CB, McCann SE, et al. (2014) Associations of dietary folate, vitamins $\mathrm{B}_{6}$ and $\mathrm{B}_{12}$ and methionine intake with risk of breast cancer among African American and European American women. Int J Cancer 134, 1422-1435.

20. Fritz H, Seely D, Flower G, et al. (2013) Soy, red clover, and isoflavones and breast cancer: a systematic review. PLOS ONE 8, e81968.

21. Sieri S, Chiodini P, Agnoli C, et al. (2014) Dietary fat intake and development of specific breast cancer subtypes. $J$ Natl Cancer Inst 106, dju068.

22. Sieri S, Krogh V, Ferrari P, et al. (2008) Dietary fat and breast cancer risk in the European Prospective Investigation into Cancer and Nutrition. Am J Clin Nutr 88, 1304-1312.

23. Sieri S, Krogh V, Muti P, et al. (2002) Fat and protein intake and subsequent breast cancer risk in postmenopausal women. Nutr Cancer 42, 10-17.

24. Cho E, Spiegelman D, Hunter DJ, et al. (2003) Premenopausal fat intake and risk of breast cancer. J Natl Cancer Inst $\mathbf{9 5}$, 1079-1085.

25. Hunter DJ, Spiegelman D, Adami HO, et al. (1996) Cohort studies of fat intake and the risk of breast cancer - a pooled analysis. $N$ Engl J Med 334, 356-361.

26. Kim EH, Willett WC, Colditz GA, et al. (2006) Dietary fat and risk of postmenopausal breast cancer in a 20-year follow-up. Am J Epidemiol 164, 990-997.

27. Smith-Warner SA, Spiegelman D, Adami HO, et al. (2001) Types of dietary fat and breast cancer: a pooled analysis of cohort studies. Int J Cancer 92, 767-774.

28. Link LB, Canchola AJ, Bernstein L, et al. (2013) Dietary patterns and breast cancer risk in the California Teachers Study cohort. Am J Clin Nutr 98, 1524-1532.

29. Buckland G, Travier N, Cottet V, et al. (2013) Adherence to the Mediterranean diet and risk of breast cancer in the European prospective investigation into cancer and nutrition cohort study. Int J Cancer 132, 2918-2927.

30. Agurs-Collins T, Rosenberg L, Makambi K, et al. (2009) Dietary patterns and breast cancer risk in women participating in the Black Women's Health Study. Am J Clin Nutr 90, 621-628. 
31. Butler LM, Wu AH, Wang R, et al. (2010) A vegetable-fruit-soy dietary pattern protects against breast cancer among postmenopausal Singapore Chinese women. Am J Clin Nutr 91, 1013-1019.

32. Cottet V, Touvier M, Fournier A, et al. (2009) Postmenopausal breast cancer risk and dietary patterns in the E3N-EPIC prospective cohort study. Am J Epidemiol 170, 1257-1267.

33. Sieri S, Krogh V, Pala V, et al. (2004) Dietary patterns and risk of breast cancer in the ORDET cohort. Cancer Epidemiol Biomarkers Prev 13, 567-572.

34. Wu AH, Yu MC, Tseng C-C, et al. (2009) Dietary patterns and breast cancer risk in Asian American women. Am J Clin Nutr 89, $1145-1154$

35. Brody JG, Rudel RA, Michels KB, et al. (2007) Environmental pollutants, diet, physical activity, body size, and breast cancer: where do we stand in research to identify opportunities for prevention? Cancer 109, 2627-2634.

36. Dos Santos Silva I, Mangtani P, McCormack V, et al. (2002) Lifelong vegetarianism and risk of breast cancer: a populationbased case-control study among South Asian migrant women living in England. Int J Cancer 99, 238-244.

37. Key TJ, Appleby PN, Spencer EA, et al. (2009) Cancer incidence in vegetarians: results from the European Prospective Investigation into Cancer and Nutrition (EPIC-Oxford). Am J Clin Nutr 89, 1620S-1626S.

38. Mills PK, Beeson WL, Phillips RL, et al. (1989) Dietary habits and breast cancer incidence among Seventh-day Adventists. Cancer 64, 582-590.

39. Travis RC, Allen NE, Appleby PN, et al. (2008) A prospective study of vegetarianism and isoflavone intake in relation to breast cancer risk in British women. Int J Cancer 122 705-710.

40. Fraser GE (2003) Diet, Life Expectancy, and Chronic Disease: Studies of Seventh-Day Adventists and Other Vegetarians. Oxford and New York, NY: Oxford University Press.

41. Butler TL, Fraser GE, Beeson WL, et al. (2008) Cohort profile: the Adventist Health Study-2 (AHS-2). Int J Epidemiol 37, 260-265.

42. Jaceldo-Siegl K, Knutsen SF, Sabate J, et al. (2010) Validation of nutrient intake using an FFQ and repeated $24 \mathrm{~h}$ recalls in black and white subjects of the Adventist Health Study-2 (AHS-2). Public Health Nutr 13, 812-819.

43. Jaceldo-Siegl K, Fan J, Sabate J, et al. (2011) Race-specific validation of food intake obtained from a comprehensive FFQ: the Adventist Health Study-2. Public Health Nutr 14, 1988-1997.

44. Rizzo NS, Jaceldo-Siegl K, Sabate J, et al. (2013) Nutrient profiles of vegetarian and nonvegetarian dietary patterns. J Acad Nutr Diet 113, 1610-1619.

45. Orlich MJ, Jaceldo-Siegl K, Sabate J, et al. (2014) Patterns of food consumption among vegetarians and non-vegetarians. Br J Nutr 112, 1644-1653.

46. Registry Plus (2010) A Suite of Publicly Available Software Programs for Collecting and Processing Cancer Registry Data. Atlanta, GA: US Department of Health and Human Services, Centers for Disease control and Prevention, National Center for Chronic Disease Prevention and Health Promotion.

47. Tantamango-Bartley $\mathrm{Y}$, Jaceldo-Siegl $\mathrm{K}$, Fan $\mathrm{J}$, et al. (2013) Vegetarian diets and the incidence of cancer in a low-risk population. Cancer Epidemiol Biomarkers Prev 22, 286-294.

48. Armstrong K, Eisen A \& Weber B (2000) Assessing the risk of breast cancer. $N$ Engl J Med 342, 564-571.
49. Green J, Cairns BJ, Casabonne D, et al. (2011) Height and cancer incidence in the Million Women Study: prospective cohort, and meta-analysis of prospective studies of height and total cancer risk. Lancet Oncol 12, 785-794.

50. Costantino JP, Gail MH, Pee D, et al. (1999) Validation studies for models projecting the risk of invasive and total breast cancer incidence. J Natl Cancer Inst 91, 1541-1548.

51. McKinlay SM, Brambilla DJ \& Posner JG (2008) The normal menopause transition. Maturitas 61, 4-16.

52. Pintilie M (2007) The $\mathrm{R}$ software and cmprsk package. In Competing Risks: a practical perspective. Appendix B1. Wiley Online Library. https://onlinelibrary.wiley.com/doi/10.1002/ 9780470870709.app2/pdf (accessed January 2015)

53. Little RJA \& Rubin DB (2002) Statistical Analysis with Missing Data, 2nd ed. Hoboken, NJ: Wiley.

54. Fraser G \& Yan R (2007) Guided multiple imputation of missing data: using a subsample to strengthen the missing-atrandom assumption. Epidemiology 18, 246-252.

55. Key TJ, Appleby PN, Spencer EA, et al. (2009) Cancer incidence in British vegetarians. Br J Cancer 101, 192-197.

56. Fung TT, Hu FB, Holmes MD, et al. (2005) Dietary patterns and the risk of postmenopausal breast cancer. Int J Cancer 116, 116-121.

57. Lagiou P, Adami HO \& Trichopoulos D (2006) Early life diet and the risk for adult breast cancer. Nutr Cancer 56, 158-161.

58. Lagiou P (2007) Intrauterine factors and breast cancer risk. Lancet Oncol 8, 1047-1048.

59. Terry P, Suzuki R, Hu FB, et al. (2001) A prospective study of major dietary patterns and the risk of breast cancer. Cancer Epidemiol Biomarkers Prev 10, 1281-1285.

60. Phillips RL (1975) Role of life-style and dietary habits in risk of cancer among seventh-day adventists. Cancer Res 35 , 3513-3522

61. Catsburg C, Miller AB \& Rohan TE (2014) Adherence to cancer prevention guidelines and risk of breast cancer. Int J Cancer 135, 2444-2452.

62. McMichael AJ (2008) Food, nutrition, physical activity and cancer prevention. Authoritative report from World Cancer Research Fund provides global update. Public Health Nutr 11, 762-763.

63. Reding KW, Zahid M, Cavalieri E, et al. (2014) Associations between dietary intake of fruits and vegetables in relation to urinary estrogen DNA adduct ratio. Open J Prev Med 4, 429-437.

64. Steinmetz KA \& Potter JD (1996) Vegetables, fruit, and cancer prevention: a review. J Am Diet Assoc 96, 1027-1039.

65. Key TJ, Appleby PN \& Rosell MS (2006) Health effects of vegetarian and vegan diets. Proc Nutr Soc 65, 35-41.

66. Xu X, Duncan AM, Wangen KE, et al. (2000) Soy consumption alters endogenous estrogen metabolism in postmenopausal women. Cancer Epidemiol Biomarkers Prev 9, 781-786.

67. McCarty MF (1999) Vegan proteins may reduce risk of cancer, obesity, and cardiovascular disease by promoting increased glucagon activity. Med Hypotheses 53, 459-485.

68. McCarty MF (2011) mTORC1 activity as a determinant of cancer risk - rationalizing the cancer-preventive effects of adiponectin, metformin, rapamycin, and low-protein vegan diets. Med Hypotheses 77, 642-648.

69. Clemmons DR \& Underwood LE (1991) Nutritional regulation of IGF-I and IGF binding proteins. Annu Rev Nutr 11, 393-412.

70. Kandaswami C, Lee LT, Lee PP, et al. (2005) The antitumor activities of flavonoids. In Vivo 19, 895-909. 